\title{
Comportamento de blocos cerâmicos estruturais produzidos a partir da mistura de lama vermelha e argila
}

Performance of structural ceramic blocks produced from red mud and clay mixture

\section{Alcebíades Negrão Macêdo \\ Diogo Henrique Pereira e Costa \\ Sandro Roberto dos Santos Trindade \\ J osé Antônio da Silva Souza \\ Ronaldson J osé de França Mendes Carneiro}

\section{Resumo}

Alcebíades Negrão Macêdo Centro Tecnológico Universidade Federal do Pará Rua Augusta Correa, 1, Jurunas Belém - PA - Brasil CEP 66075-110 Tel.: (91) 211-1679 E-mail: anmacedo@ufpa.br

Diogo Henrique Pereira e Costa Centro Tecnológico Universidade Federal do Pará E-mail: diogohpc@gmail.com

Sandro Roberto dos Santos Trindade Centro Tecnológico Universidade Federal do Pará E-mail: sroberto@ufpa.br

J osé Antônio da Silva Souza Centro Tecnológico Universidade Federal do Pará E-mail: jass@ufpa.br

Ronaldson J osé de França Mendes Carneiro Centro Tecnológico Universidade Federal do Pará Tel.: (91) 3201-7317 E-mail: ronaldso@ufpa.br

Recebido em 14/04/11 Aceito em 01/12/11
A

utilização de novas técnicas de aproveitamento de resíduos tem-se tornado cada vez mais importante na construção civil, principalmente quando se trata da utilização de resíduos de outros segmentos industriais e da redução de consumo de matérias-primas naturais. $\mathrm{O}$ objetivo deste estudo foi avaliar a utilização da lama vermelha, resíduo proveniente da produção de alumina metalúrgica, na produção de blocos cerâmicos vazados estruturais. A produção dos blocos foi realizada em uma indústria cerâmica, a partir de uma mistura de 60\% de lama vermelha (LV) e de $40 \%$ de argila. Após a produção dos blocos, realizaram-se ensaios de acordo com as normas técnicas, tais como absorção de água e compressão axial simples. A partir da análise dos resultados, observou-se que os blocos estruturais produzidos a partir da mistura de LV e argila atenderam aos parâmetros normativos quanto ao índice de absorção de água e de resistência à compressão, e que as resistências médias e características desses blocos foram superiores às dos blocos cerâmicos de referência.

Palavras-chave: Lama vermelha. Argila. Alvenaria estrutural. Blocos cerâmicos.

\section{Abstract}

The use of new techniques for waste reuse has become increasingly important in construction, especially when it deals with the use of waste from other industries and reduction on the consumption of natural materials. The purpose of this study was to evaluate the use of red mud (LV) waste, alumina metallurgical residue, on the production of structural ceramic blocks. The production of the blocks was carried out at a ceramic industry, using a mixture of $60 \%$ of red mud and $40 \%$ of clay. After the production of blocks, tests were conducted according to technical standards, such as water absorption and simple axial compression. From the analysis of the results, the conclusion was made that that structural blocks, made from the mixture of clay and $L V$, complied the standard parameters related to the rate of water absorption and compressive strength, and that the strength of theses blocks was significantly higher than those made from 100\% clay.

Keywords: Red mud. Clay. Masonry structural. Ceramic blocks. 


\section{Introdução}

A lama vermelha (LV) não é classificada como um resíduo perigoso segundo a United States Environmental Protection Agency (ENVIRONMENTAL..., 2005), porém sua produção nas fábricas de alumina constitui um problema ambiental, devido ao teor cáustico pela presença de $\mathrm{Na}(\mathrm{OH})$, que leva o $\mathrm{pH}$ da $\mathrm{LV}$ para valores entre 12 e 14, tornando-se a principal fonte de cuidados e segurança, pois acidentes podem tomar proporções consideráveis em função da quantidade produzida. Na literatura não existe a definição de uma proporção exata entre a quantidade de alumina produzida e quantidade de LV gerada (SILVA FILHO; ALVES; DA MOTTA, 2007), porém há referência que uma fábrica típica de alumina produza de 1 a 2 toneladas de lama vermelha por tonelada de alumina produzida (HIND; BHARGAVA; GROCOTT, 1999; BRUNORI et al., 2005).

Somente a Alunorte - Alumina do Norte do Brasil S.A., localizada em Barcarena, PA, produziu 5,03 milhões de toneladas de alumina calcinada em 2008 (ALUNORTE, 2008). Estima-se que somente nessa fábrica foram produzidos cerca de 6 milhões de toneladas de lama vermelha em 2010. Outro fator importante é que o material possui ainda uma quantidade de $\mathrm{NaOH}$ em torno de $8 \%$ em peso, o que explica a causticidade presente na lama vermelha. Esse material apresenta um teor de compostos de ferro bastante elevado, podendo ainda estar presentes óxidos de V, Ga, P, Mn, Mg, $\mathrm{Zn}$, Th, Cr e Nb, que podem contaminar cursos d'água e lençóis subterrâneos, além dos elevados custos para sua deposição. Por outro lado, a indústria cerâmica, que produz insumos para a construção civil, tem-se apresentado como uma excelente alternativa para o aproveitamento de resíduos de diferentes segmentos industriais. Estudos realizados mostraram que a LV apresenta boas características para a aplicação na produção de artefatos cerâmicos (HILDEBRANDO, 1998; GOUVEIA, 2006; SILVA FILHO; ALVES; DA MOTTA, 2007; SOUZA et. al.; 2010; SOUZA, 2010).

Por outro lado, o processo construtivo utilizando alvenaria estrutural tem-se destacado na construção civil, devido a sua eficiência, funcionalidade e baixo custo, proporcionando uma edificação mais econômica, mais limpa e de elevada velocidade de construção, pelo fato de os blocos estruturais dispensarem a confecção de vigas e pilares de concreto armado e, por consequência, a confecção de fôrmas de madeira e armaduras, reforçando o atual quadro da construção civil em buscar soluções que impliquem o aumento racional da produtividade e a eliminação de desperdícios. No entanto, tanto os blocos estruturais de concreto quanto os cerâmicos devem apresentar características físicas e mecânicas adequadas para tal finalidade. Dentro desse contexto, o presente trabalho tem como objetivo avaliar o comportamento de blocos cerâmicos produzidos a partir da mistura de LV e argila como uma alternativa para aplicação estrutural, que pode contribuir para a redução dos impactos ambientais ocasionados pela deposição de LV e extração de argila, além de eventuais reduções de custo de produtos finais.

\section{Revisão bibliográfica \\ Considerações sobre a LV em produtos cerâmicos}

A lama vermelha (LV) consiste no resíduo dos componentes minerais insolúveis provenientes da digestão da bauxita pelas soluções de hidróxido de sódio, na fabricação de alumina pelo processo Bayer (HILDEBRANDO, 1998). É composta principalmente de óxido de ferro, quartzo, aluminossilicatos de sódio, carbonato de cálcio/aluminato, dióxido de titânio e hidróxido de sódio (NORTON, 1973), sendo considerada como um resíduo de classe II, não inerte (LIMA, 2006).

A composição química da LV varia bastante dependendo da natureza da bauxita e da técnica empregada no processo Bayer em cada indústria. Geralmente, a LV retém todo o ferro, titânio e sílica presentes na bauxita, além do alumínio não extraído durante o refino, combinado com o sódio sob a forma de um silicato hidratado de alumínio e sódio de natureza zeolítica (REESE; CUNDIFF, 1955; DAVIES-MCCONCHIE et al., $2002^{1}$ apud SILVA FILHO; ALVES; DA MOTTA, 2007). Existem relatos de que a composição química da LV pode variar até em função do tempo de deposição e do grau de exposição com o ar ambiente, perda de seu teor de causticidade, por exemplo (SILVA FILHO; ALVES; DA MOTTA, 2007). A Tabela 1 apresenta algumas variações nas propriedades químicas da LV.

No caso da indústria cerâmica as argilas cauliníticas utilizadas como matéria-prima já apresentam uma relação sílica/alumina suficiente para as reações características dos silicoaluminatos

\footnotetext{
${ }^{1}$ MCCONCHIE, D.; CLARK, M.; DAVIES-MCCONCHIE, F. New Strategies for the Management of Bauxite Refinery Residues (Red Mud). In: INTERNATIONAL ALUMINA QUALITY WORKSHOP, 6., Brisbane, Australia, 2002. Proceedings... Brisbane, Australia, 2002. p. 327-332.
} 
e índices de ferro acima de 10\% em massa, além da presença de titânio e alcalinos, substâncias importantes para as reações de estado sólido, responsáveis pela sinterização (SOUZA, 2006; SOUZA; MACÊDO; QUARESMA, 2002). Dessa forma, a LV mostra-se um importante componente na mistura, contribuindo para a redução de porosidade e para o aumento de resistência mecânica do material. A LV apresenta elevados teores de ferro, além de sódio, cálcio e outros elementos chamados cátions vitrificantes (fundentes), que agregam características importantes aos produtos cerâmicos, tais como aumento da resistência mecânica e redução de porosidade. Na Figura 1 são mostradas as difrações de raios X para uma amostra de LV da Alumina do Norte do Brasil S.A. - Alunorte e uma argila caulinítica com presença laterítica (APCA), utilizada na indústria cerâmica da região, mostrando a presença das fases responsáveis pelas reações de estado sólido na sinterização.

$\mathrm{O}$ aumento no teor de LV em misturas com argila implica uma maior quantidade de fundentes (Fe, $\mathrm{Na}$ ) presentes na massa, aumentando a eficiência de reações de estado sólido, formando mais fase amorfa pela presença de mais sódio $(\mathrm{Na})$ e ferro
(Fe). As reações de estado sólido entre o sódio (Na) e a sílica livre $\left(\mathrm{S}_{\mathrm{i}} \mathrm{O}_{2}\right)$ representam a formação de mais fase amorfa (vidro) e, consequentemente, melhoria na sinterização, com redução de porosidade, e como reação complementar, o aumento do teor de mulita secundária, resultando em aumento de resistência mecânica (VIEIRA, 2008; SOUZA, 2010). Essa característica é a vantagem do uso de fundentes eficientes, presentes na lama vermelha, uma vez que se pode obter componentes cerâmicos mais resistentes sem necessariamente aumentar a temperatura de sinterização.

O cuidado que se deve ter nesse processo é procurar avaliar a dosagem ótima de adição de LV na mistura com argila em função do tipo de produto a ser fabricado e o nível de temperatura de sinterização. O controle de temperatura é importante para garantir que todo o material esteja sinterizado para que não haja liberação de material cáustico. Estudos sobre lixiviação e solubilização da mistura LV e argila mostraram não haver residual cáustico para o material queimado a partir de $750{ }^{\circ} \mathrm{C}$ (SOUZA; NEVES; HILDEBRANDO, 2000; SANTOS; OROFINO; SOUZA, 2001).

Tabela 1 - Composição química da LV por diferentes fontes (\%)

\begin{tabular}{ccccccc}
\hline Composto & ALUNORTE & ALCOA & CBA & $\begin{array}{c}\text { ALCAN } \\
\text { Canadá }\end{array}$ & $\begin{array}{c}\text { ALCOA } \\
\text { Austrália }\end{array}$ & $\begin{array}{c}\text { ALCAN África } \\
\text { ALa }\end{array}$ \\
\hline $\mathrm{Al}_{2} \mathrm{O}_{3}$ & 35,50 & 35,67 & 36,70 & 37,60 & 25,45 & 26,60 \\
$\mathrm{Fe}_{2} \mathrm{O}_{3}$ & 37,16 & 33,78 & 29,89 & 32,45 & 34,50 & 48,40 \\
$\mathrm{SiO}_{2}$ & 2,34 & 3,45 & 6,78 & 3,67 & 17,06 & 5,50 \\
$\mathrm{TiO}_{2}$ & 6,18 & 4,56 & 5,67 & 4,12 & 4,90 & 2,80 \\
$\mathrm{Na}_{2} \mathrm{O}$ & 8,49 & 9,67 & 7,89 & 6,78 & 2,74 & 2,40 \\
$\mathrm{CaO}$ & 1,23 & 2,34 & 1,20 & 3,45 & 3,69 & - \\
$\mathrm{MgO}$ & - & - & - & - & - & - \\
$\mathrm{PF}$ (perda ao fogo) & 11,19 & 11,24 & 12,35 & 9,80 & 12,90 & 14,60 \\
\hline
\end{tabular}

Fonte: Silva Filho, Alves e Da Motta (2007).

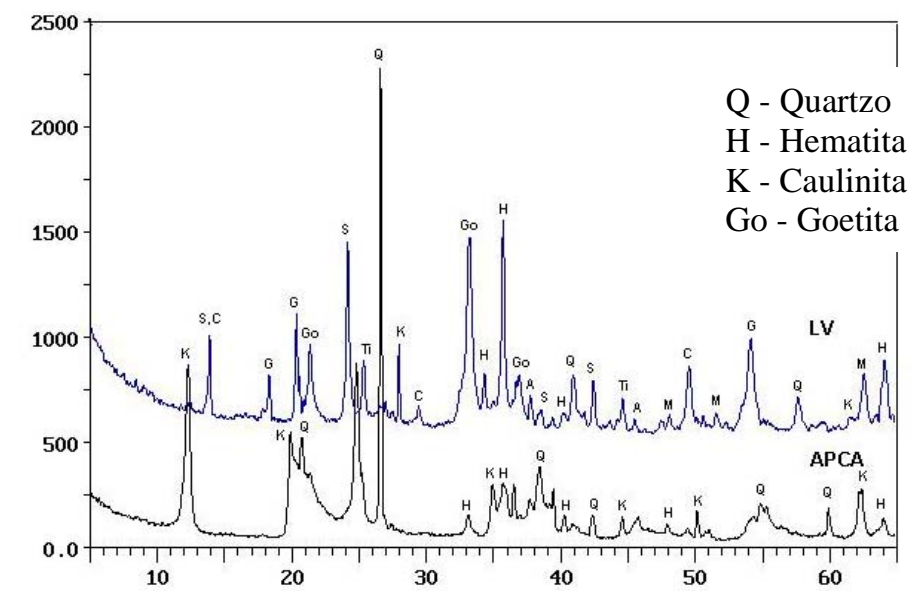

Figura 1 - Difração de raios $X$ da argila e da LV in natura

Nota: Vieira (2008). 
Para blocos cerâmicos de vedação e estruturais, o excesso de LV na mistura com argila pode gerar retrações acentuadas na fase de secagem ao ar, introduzindo ao produto trincas por retrações que comprometem a qualidade do produto final. No trabalho de Gouveia (2006), onde foram avaliados aspectos de fabricação de blocos cerâmicos com características estruturais, observou-se que, se o teor de LV na mistura com argila ultrapassar 60\%, provavelmente o produto final será prejudicado pela retração excessiva na fase de secagem ao ar. Esse fenômeno está relacionado com a presença de zeólitas na composição da LV. As zeólitas possuem propriedades importantes de adsorção devido a sua elevada área superficial, com grande retenção de umidade e material orgânico, que, ao serem retiradas na secagem, produzem redução brusca de volume, causando trincas e fissuras nessa etapa do processo.

\section{Materiais e métodos}

Nesta seção são apresentados os materiais e os procedimentos adotados para a produção dos blocos, assim como o processo de execução dos ensaios.

\section{Materiais (lama vermelha e argila)}

A LV, resultante do processo de clarificação da bauxita pelo processo Bayer, foi cedida pela empresa Alunorte, localizada no município de Barcarena, PA. O material foi transportado até uma indústria cerâmica localizada no município de São Miguel do Guamá, PA. A argila utilizada foi retirada de jazidas situadas próximo à indústria cerâmica. As composições químicas tanto da LV quanto da argila foram determinadas no
Laboratório de Engenharia Química (LEQ) da UFPA e são apresentadas na Tabela 2.

A argila utilizada é comumente empregada pela indústria de cerâmica vermelha do parque industrial de São Miguel do Guamá, PA, possuindo composição média idêntica à de outras regiões produtoras do nordeste desse estado, sendo caracterizada como argila caulinítica, com gênese tipicamente proveniente de micas, o que justifica a presença de minerais de ferro, abundantes em toda a bacia sedimentar do Amazonas.

\section{Produção dos blocos cerâmicos}

Os blocos foram produzidos visando atender ao padrão nominal correspondente às dimensões de $14 \mathrm{~cm}$ de largura (L), $19 \mathrm{~cm}$ de altura (H) e $29 \mathrm{~cm}$ de comprimento (C) da NBR 7171 (ABNT, 1992). Foram confeccionados blocos com 100\% argila (REF), para servir de referência, e da mistura com proporções de $40 \%$ de argila e de $60 \%$ de LV em massa. Os dois componentes eram previamente misturados com o auxílio de uma pá mecânica e posteriormente colocados em um sistema de esteiras que alimenta as extrusoras. Esse processo pode ocasionar variações na dosagem dos componentes e, consequentemente, alterações nas propriedades do bloco. A seção transversal dos blocos cerâmicos de referência e com a mistura LV e argila foi moldada segundo duas geometrias:

(a) a primeira correspondente a um padrão reticulado $(R)$, usualmente utilizada no mercado; e

(b) a segunda, de padrão circular (C), adaptada a partir do trabalho de Gouveia (2006) (Figura 2).

A espessura mínima dos septos no caso dos blocos com geometria reticulada obedeceu à NBR 152702 (ABNT, 2005a).

Tabela 2 - Composição química da LV e da argila

\begin{tabular}{crr}
\hline Constituintes & Lama vermelha & Argila \\
\hline $\mathrm{SiO}_{2}$ & 17,90 & 62,80 \\
$\mathrm{Al}_{2} \mathrm{O}_{3}$ & 18,00 & 21,50 \\
$\mathrm{Fe}_{2} \mathrm{O}_{3}$ & 39,00 & 4,56 \\
$\mathrm{TiO}_{2}$ & 7,9, & 1,07 \\
$\mathrm{CaO}$ & 0,87 & 0,02 \\
$\mathrm{Na}_{2} \mathrm{O}$ & 6,58 & $*$ \\
$\mathrm{~V}_{2} \mathrm{O}_{5}$ & $*$ & $*$ \\
$\mathrm{~K}_{2} \mathrm{O}$ & 0,12 & 0,07 \\
$\mathrm{MgO}$ & 0,04 & 0,23 \\
$\mathrm{~V}, \mathrm{Ga}, \mathrm{P}, \mathrm{Mn}, \mathrm{Mg}, \mathrm{Zn}$, & $*$ & $*$ \\
$\mathrm{Zr}, \mathrm{Th}, \mathrm{Cr}, \mathrm{Nb}$ & & \\
$\mathrm{PF}$ (perda ao fogo) & 11,10 & 9,89 \\
\hline
\end{tabular}

28 Macêdo, A. N.; Pereira e Costa, D. H.; Trindade, S. R. dos S. ; Souza, J. A. da S.; Carneiro, R. J . de F. M. 

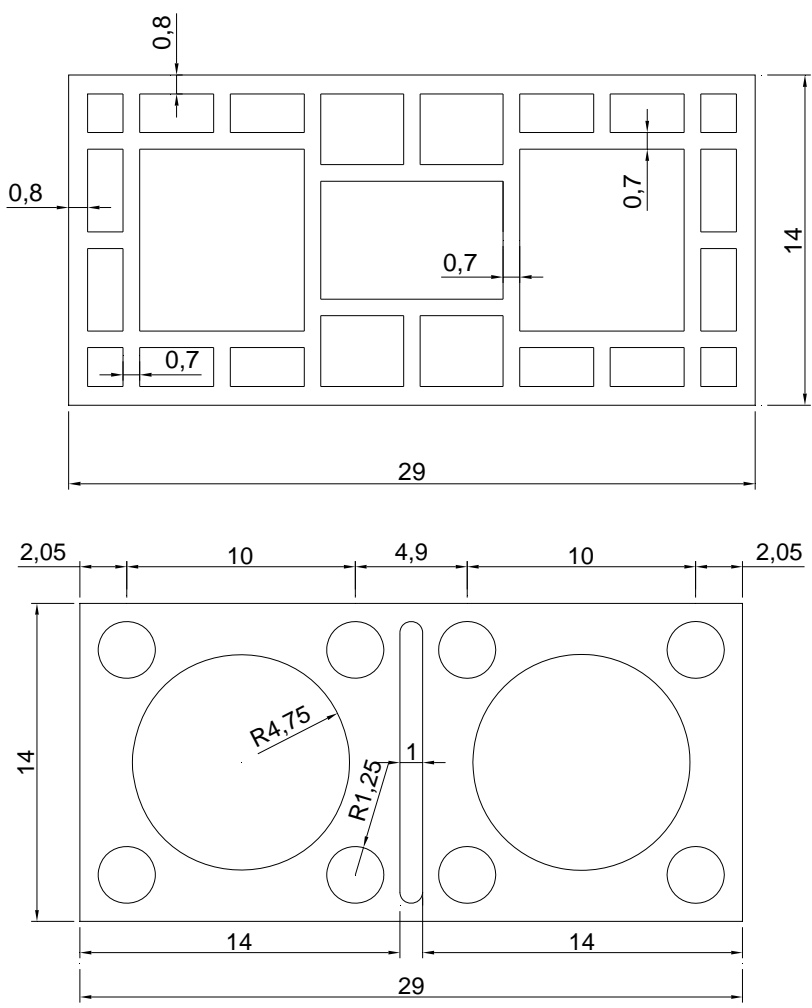

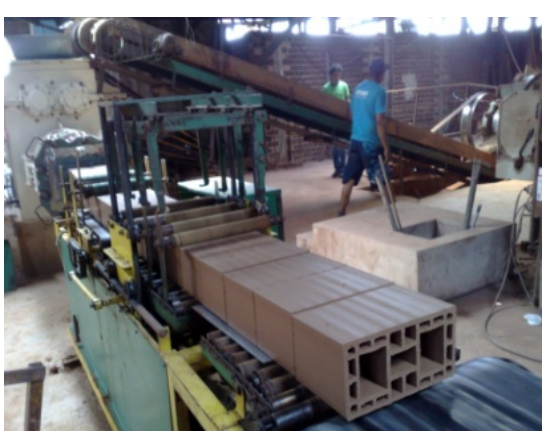

(a)

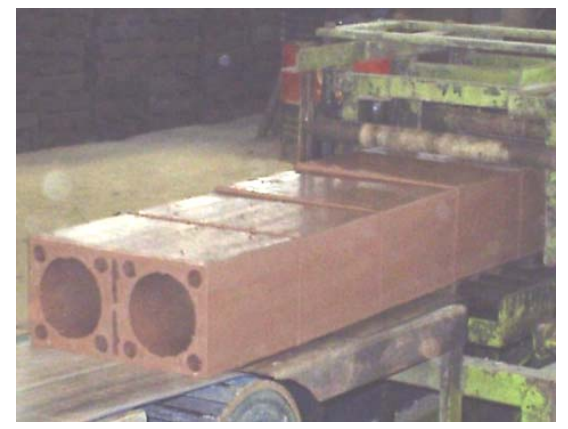

(b)

Figura 2 - Geometria dos blocos: (a) padrão reticulado e (b) padrão circular

Nota: dimensões em cm.

Após a moldagem, todos os blocos foram acondicionados em prateleiras abrigadas e submetidos a uma secagem à temperatura ambiente, por um período mínimo de $48 \mathrm{~h}$, para evitar o surgimento de trincas devido à retração. Em seguida foram levados ao forno fechado para a sinterização a uma temperatura de aproximadamente $950{ }^{\circ} \mathrm{C}$. Essa temperatura foi definida por se considerar que para esse nível o material torna-se inerte após a sinterização, ou seja, todo o $\mathrm{Na}(\mathrm{OH})$ reage com a sílica para formar vidro e auxiliar na formação da mulita, além de ser a temperatura usual na indústria cerâmica na região.

\section{Ensaios}

\section{Propriedades físicas}

Foram realizados ensaios de absorção de água e caracterizações quanto a dimensões (largura, altura, comprimento e espessura dos septos) para os blocos de geometria reticulada com mistura de LV e argila (LVA-R) e os blocos de referência (REF-R) segundo as recomendações da NBR 15270-3 (ABNT, 2005b). O índice de absorção de água (AA) foi determinado de acordo com a Equação 1, NBR 15270-3 (ABNT, 2005b):

$$
\mathrm{AA}(\%)=\frac{\mathrm{m}_{\mathrm{u}}-\mathrm{m}_{\mathrm{s}}}{\mathrm{m}_{\mathrm{s}}} \cdot 100
$$

Para a determinação da massa seca $\left(\mathrm{m}_{\mathrm{s}}\right)$, foi realizada a secagem dos blocos em estufa, a uma temperatura de $105 \pm 5{ }^{\circ} \mathrm{C}$, tendo sido eles pesados em intervalos de $1 \mathrm{~h}$, até que apresentassem estabilização no valor da massa. Após esse procedimento iniciou-se a determinação da massa úmida $\left(\mathrm{m}_{\mathrm{u}}\right)$, quando os blocos foram colocados em um recipiente com água, à temperatura ambiente, por um período igual ou superior a $24 \mathrm{~h}$, até que atingissem as condições de valores constantes para a massa. Todas as medidas de massa foram realizadas em balança, com precisão de centésimo de grama, disponível no Laboratório de Engenharia Civil da Universidade Federal do Pará, e a variação máxima admitida nas pesagens foi de $0,25 \%$.

As dimensões dos septos foram medidas com paquímetros digitais com precisão de centésimos de milímetros. As amostras utilizadas para os ensaios de absorção foram as mesmas utilizadas para a determinação das dimensões, consistindo em um número de 12 blocos para cada conjunto. 


\section{Resistência à compressão}

Foram separados para os ensaios de resistência à compressão quatro conjuntos de blocos cerâmicos com 12 amostras cada, dois com mistura de LV e argila, e dois de referência, correspondentes às geometrias de seção reticular e circular respectivamente. Esses blocos foram capeados com pasta de cimento (Figura 3a). Após o endurecimento da pasta de cimento e a regularização das superfícies, os blocos foram imersos em água potável até que estivessem totalmente saturados (Figura 3b), de acordo com a NBR 15270-3 (ABNT, 2005b).

Os quatro conjuntos de blocos foram ensaiados à compressão, com controle de carga, em uma máquina universal AMSLER de $2.000 \mathrm{kN}$, com acionamento hidráulico, disponível no Laboratório de Engenharia Civil da UFPA (Figura 4). A velocidade de carga estimada para o ensaio foi de 0,05 $\pm 0,01 \mathrm{MPa} / \mathrm{s}$, conforme recomendado pela NBR 15270-3 (ABNT, 2005b).

A determinação da resistência à compressão dos blocos individuais é calculada com referência à área bruta. As resistências médias e características foram determinadas com auxílio de planilha eletrônica, seguindo as recomendações da NBR 15270-2 (ABNT, 2005a) para a determinação da resistência característica (Equação 2).

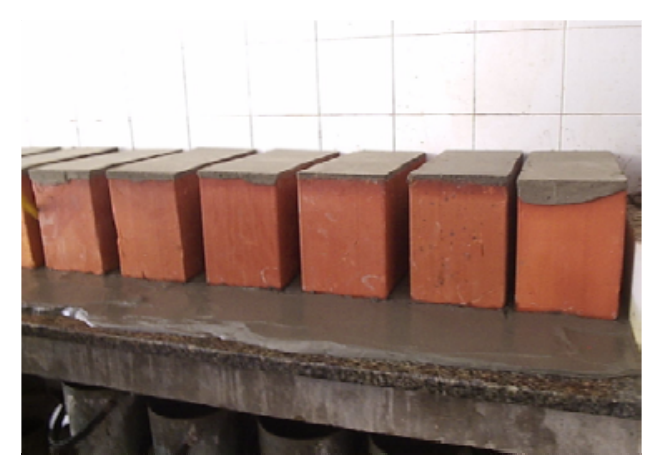

(a) $\mathrm{f}_{\mathrm{bk}}=2 \cdot\left[\frac{\mathrm{f}_{\mathrm{b}(1)}+\mathrm{f}_{\mathrm{b}(2)}+\ldots+\mathrm{f}_{\mathrm{b}(\mathrm{i}-1)}}{\mathrm{i}-1}\right]-\mathrm{f}_{\mathrm{b}(\mathrm{i})}$

Onde:

$f_{b(1)}, f_{b(2)}, \ldots, f_{b(i)}$ são os valores de resistência à compressão individual, ordenados crescentemente;

$\mathrm{i}=\mathrm{n} / 2$ se $\mathrm{n}$ for par; e

$\mathrm{i}=(\mathrm{n}-1) / 2$ se $\mathrm{n}$ for ímpar;

n é a quantidade de blocos da amostra.

Se o valor de $f_{b k}$ obtido pela equação 1 for inferior a $\mathrm{f}_{\mathrm{b}(1)}$, a norma recomenda que $\mathrm{f}_{\mathrm{bk}}=\phi . \mathrm{f}_{\mathrm{b}(1)}$, com $\phi=$ 0,98 para $n=12$.

\section{Resultados}

\section{Propriedades físicas}

As tolerâncias dimensionais dos blocos, de acordo com a NBR 15270-2 (ABNT, 2005a), são apresentadas na Quadro 1. Nas Tabelas 3 e 4 são apresentados os resultados dos ensaios de absorção de água (AA) e das caracterizações dimensionais dos blocos com geometria reticular considerando a mistura de LV e argila (LVA-R) e para os blocos de referência (REF-R).

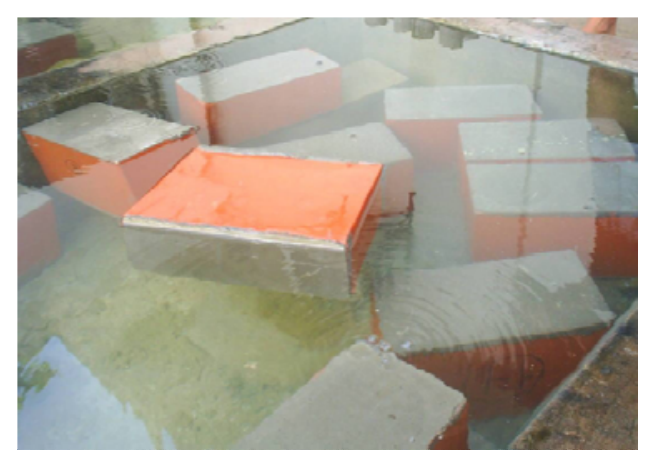

(b)

Figura 3 - Preparação dos blocos: (a) capeamento e (b) saturação
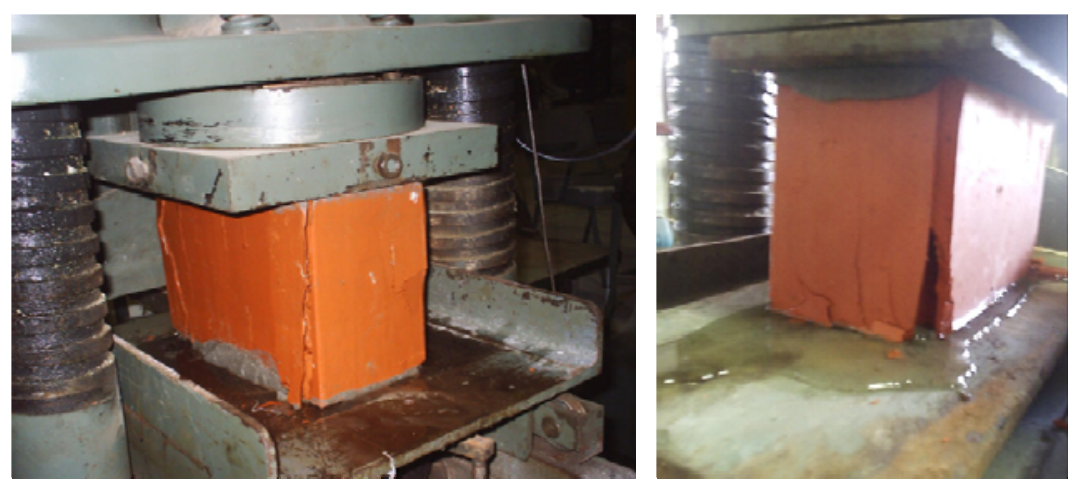

Figura 4 - Ensaio de resistência à compressão

30 Macêdo, A. N.; Pereira e Costa, D. H.; Trindade, S. R. dos S.; Souza, J. A. da S.; Carneiro, R. J . de F. M. 
Quadro 1 - Tolerâncias dimensionais

\begin{tabular}{|l|c|c|}
\hline $\begin{array}{c}\text { Grandezas } \\
\text { controladas }\end{array}$ & $\begin{array}{c}\text { Tolerâncias dimensionais } \\
\text { individuais relacionadas à } \\
\text { dimensão efetiva (mm) }\end{array}$ & $\begin{array}{c}\text { Tolerâncias dimensionais } \\
\text { relacionadas à média das } \\
\text { dimensões efetivas (mm) }\end{array}$ \\
\cline { 1 - 1 } Largura (L) & \pm 5 & \pm 3 \\
\cline { 1 - 1 } Altura (H) & \pm 5 (H) & \\
\cline { 1 - 1 } Comprimento (C) & & \\
\hline
\end{tabular}

Tabela 3 - Dimensões e absorção de água - blocos estruturais de LVA-R

\begin{tabular}{|c|c|c|c|c|c|c|c|c|}
\hline \multicolumn{9}{|c|}{ Bloco estrutural de LVA com geometria reticulada } \\
\hline $\mathbf{C P}$ & $\begin{array}{l}\text { Largura } \\
\text { (L) }\end{array}$ & $\begin{array}{l}\text { Altura } \\
\text { (H) }\end{array}$ & $\begin{array}{c}\text { Comprimento } \\
\text { (C) }\end{array}$ & $\begin{array}{c}\text { Borda } \\
\text { externa }\end{array}$ & Septos & $\begin{array}{c}\text { Massa seca } \\
\left(\mathbf{m}_{\mathrm{s}}\right)\end{array}$ & $\begin{array}{c}\text { Massa } \\
\text { úmida }\left(\mathbf{m}_{\mathrm{u}}\right)\end{array}$ & $\begin{array}{c}\text { Absorção de } \\
\text { água (AA) }\end{array}$ \\
\hline $\mathbf{N}^{\mathbf{0}}$ & & & $(\mathbf{c m})$ & & & & ) & $(\%)$ \\
\hline 1 & 13,5 & 18,0 & 28,5 & 0,9 & 0,7 & 5.477 & 5.996 & 9,48 \\
\hline 2 & 13,5 & 18,0 & 28,0 & 0,9 & 0,8 & 5.483 & 5.995 & 9,34 \\
\hline 3 & 13,5 & 18,0 & 28,0 & 0,8 & 0,7 & 5.490 & 5.935 & 8,11 \\
\hline 4 & 13,5 & 18,0 & 28,5 & 0,9 & 0,8 & 5.496 & 5.995 & 9,08 \\
\hline 5 & 13,5 & 18,5 & 28,5 & 0,9 & 0,7 & 5.542 & 6.116 & 10,36 \\
\hline 6 & 13,0 & 18,0 & 28,5 & 0,9 & 0,8 & 5.559 & 6.069 & 9,17 \\
\hline 7 & 13,8 & 18,2 & 28,9 & 0,9 & 0,8 & 5.332 & 5.792 & 8,63 \\
\hline 8 & 13,8 & 18,4 & 29,0 & 0,9 & 0,8 & 6.200 & 6.817 & 9,95 \\
\hline 9 & 13,3 & 17,9 & 28,0 & 0,9 & 0,9 & 5.450 & 5.921 & 8,64 \\
\hline 10 & 13,8 & 18,5 & 29,0 & 1,0 & 0,9 & 5.490 & 5.960 & 8,56 \\
\hline 11 & 13,4 & 17,9 & 28,3 & 0,9 & 1,0 & 5.416 & 5.914 & 9,19 \\
\hline 12 & 13,9 & 18,6 & 29,2 & 1,0 & 0,9 & 5.750 & 6.375 & 10,87 \\
\hline Média & 13,5 & 18,2 & 28,5 & 0,9 & 0,8 & 5.557 & 6.074 & 9,28 \\
\hline Desv. Pad. & 0,3 & 0,3 & 0,4 & 0,1 & 0,1 & 225,1 & 273,7 & 0,80 \\
\hline Coef. Var. & 0,0 & $\mathbf{0 , 0}$ & $\mathbf{0 , 0}$ & 0,1 & 0,1 & 0,0 & 0,0 & 0,09 \\
\hline
\end{tabular}

Tabela 4 - Dimensões e absorção de água - blocos estruturais de REF-R

\begin{tabular}{|c|c|c|c|c|c|c|c|c|}
\hline \multicolumn{9}{|c|}{ Bloco estrutural de REF com geometria reticulada } \\
\hline $\mathbf{C P}$ & $\begin{array}{l}\text { Largura } \\
\text { (L) }\end{array}$ & $\begin{array}{c}\text { Altura } \\
\text { (H) }\end{array}$ & $\begin{array}{c}\text { Comprimento } \\
\text { (C) }\end{array}$ & $\begin{array}{c}\text { Borda } \\
\text { Externa }\end{array}$ & Septos & $\begin{array}{c}\text { Massa seca } \\
\left(\mathbf{m}_{\mathrm{s}}\right)\end{array}$ & $\begin{array}{c}\text { Massa } \\
\text { úmida }\left(\mathrm{m}_{\mathrm{u}}\right)\end{array}$ & $\begin{array}{c}\text { Absorção de } \\
\text { água (AA) }\end{array}$ \\
\hline $\mathbf{N}^{\mathbf{0}}$ & \multicolumn{5}{|c|}{$(\mathrm{cm})$} & \multicolumn{2}{|c|}{ (g) } & $(\%)$ \\
\hline 1 & 14 & 18,5 & 29,5 & 0,9 & 0,8 & 5.130 & 5.825 & 13,55 \\
\hline 2 & 14 & 19,0 & 29,5 & 0,9 & 0,8 & 5.247 & 5.940 & 13,21 \\
\hline 3 & 14 & 18,5 & 29,5 & 0,9 & 0,7 & 5.186 & 5.873 & 13,25 \\
\hline 4 & 13,8 & 18,5 & 29,5 & 0,8 & 0,8 & 5.127 & 5.789 & 12,91 \\
\hline 5 & 14 & 19,0 & 29,0 & 0,9 & 0,8 & 5.125 & 5.802 & 13,21 \\
\hline 6 & 14 & 19,0 & 29,5 & 0,8 & 0,7 & 5.221 & 5.910 & 13,20 \\
\hline 7 & 14 & 18,5 & 29,0 & 0,9 & 0,7 & 5.101 & 5.805 & 13,80 \\
\hline 8 & 14 & 18,5 & 29,5 & 0,9 & 0,8 & 5.126 & 5.830 & 13,73 \\
\hline 9 & 13,9 & 18,5 & 29,0 & 0,9 & 0,8 & 5.115 & 5.790 & 13,20 \\
\hline 10 & 13,9 & 18,5 & 29,5 & 0,9 & 0,8 & 5.172 & 5.861 & 13,32 \\
\hline 11 & 13,9 & 18,5 & 29,4 & 0,9 & 0,8 & 5.172 & 5.842 & 12,95 \\
\hline 12 & 13,8 & 18,5 & 29,2 & 0,9 & 0,7 & 5.135 & 5.812 & 13,18 \\
\hline Média & 13,9 & 18,6 & 29,3 & 0,9 & 0,8 & 5.155 & 5.840 & 13,29 \\
\hline Desv. Pad. & 0,1 & 0,2 & 0,2 & 0,0 & 0,0 & 45,2 & 48,0 & 0,27 \\
\hline Coef. Var. & $\mathbf{0 , 0}$ & 0,0 & 0,0 & $\mathbf{0 , 0}$ & 0,1 & $\mathbf{0 , 0}$ & $\mathbf{0 , 0}$ & 2,06 \\
\hline
\end{tabular}

As variações dimensionais dos blocos, ocorridas durante a fase de sinterização, foram mais acentuadas nos blocos com mistura de LV e argila. As tolerâncias dimensionais individuais de $\pm 5 \mathrm{~mm}$ relacionadas às dimensões efetivas ( $\mathrm{L}, \mathrm{H}$ e $\mathrm{C})$ e a tolerância $\pm 3 \mathrm{~mm}$ relacionadas às médias das dimensões efetivas, recomendadas pela NBR 15270-2 (ABNT, 2005a), foram plenamente 
atendidas apenas para os blocos de referência. Já para os blocos com a mistura de LV e argila foram observadas mais de duas amostras para cada dimensão individual que não atendem aos limites normativos (Quadro 1), e todas as médias não atendem às tolerâncias dimensionais relacionadas às médias das dimensões efetivas.

Quanto ao índice de absorção de água, de acordo com a NBR 15270-3 (ABNT, 2005b), todas as amostras estavam dentro da variação de $8 \%$ a $25 \%$, estabelecida por norma, e que são compatíveis com os índices encontrados por Pedroti et al. (2007) para blocos cerâmicos queimados a uma temperatura de $1.000{ }^{\circ} \mathrm{C}$. Entretanto, observou-se um nível de absorção inferior para as amostras com a mistura de LV e argila. A menor absorção para as amostras com LV é explicada pela presença de zeólitas, que forçam uma grande redução de volume por ocasião das operações de secagem e queima, com índices de retração linear acima de $10 \%$, o que pode ser reduzido com maior controle da velocidade de secagem e da temperatura de queima.

\section{Resistência à compressão}

Os resultados de resistências à compressão médias e características e o desvio padrão para cada conjunto de blocos são apresentados nas Tabelas 5 e 6 .

Tabela 5 - Resistência à compressão - padrão reticulado

\begin{tabular}{ccc}
\hline \multirow{2}{*}{ Bloco } & $\begin{array}{c}\text { LVA-R } \\
\text { Resistência (MPa) }\end{array}$ & $\begin{array}{c}\text { REF-R } \\
\text { Resistência (MPa) }\end{array}$ \\
\hline 1 & 17,7 & 4,3 \\
2 & 19,6 & 4,4 \\
3 & 7,3 & 3,8 \\
4 & 13,9 & 4,2 \\
5 & 11,1 & 4,1 \\
6 & 16,4 & 4,3 \\
7 & 8,8 & 3,3 \\
8 & 12,4 & 4,8 \\
9 & 11,3 & 4,7 \\
10 & 7,5 & 4,3 \\
11 & 12,4 & 3,2 \\
12 & 14,0 & 3,8 \\
\hline Característica & $\mathbf{7 , 2}$ & $\mathbf{3 , 1}$ \\
\hline Média & $\mathbf{1 2 , 7}$ & $\mathbf{4 , 1}$ \\
\hline Desvio padrão & $\mathbf{3 , 9}$ & $\mathbf{0 , 5}$ \\
\hline
\end{tabular}

Tabela 6 - Resistência à compressão - padrão circular

\begin{tabular}{ccc}
\hline \multirow{2}{*}{ Bloco } & LVA-C & REF-C \\
\cline { 2 - 3 } & Resistência (MPa) & Resistência (MPa) \\
\hline 1 & 12,8 & 3,9 \\
2 & 13,2 & 4,0 \\
3 & 14,9 & 3,5 \\
4 & 4,6 & 4,0 \\
5 & 11,6 & 4,2 \\
6 & 6,3 & 4,2 \\
7 & 10,3 & 3,3 \\
8 & 13,3 & 4,5 \\
9 & 17,0 & 4,4 \\
10 & 13,4 & 3,7 \\
11 & 7,7 & 3,3 \\
12 & 12,4 & 4,0 \\
\hline Característica & $\mathbf{4 , 5}$ & $\mathbf{3 , 2}$ \\
\hline Média & $\mathbf{1 1 , 5}$ & $\mathbf{4 , 0}$ \\
\hline Desvio padrão & $\mathbf{3 , 6}$ & $\mathbf{0 , 5}$ \\
\hline
\end{tabular}

32 Macêdo, A. N.; Pereira e Costa, D. H.; Trindade, S. R. dos S.; Souza, J. A. da S.; Carneiro, R. J. de F. M. 


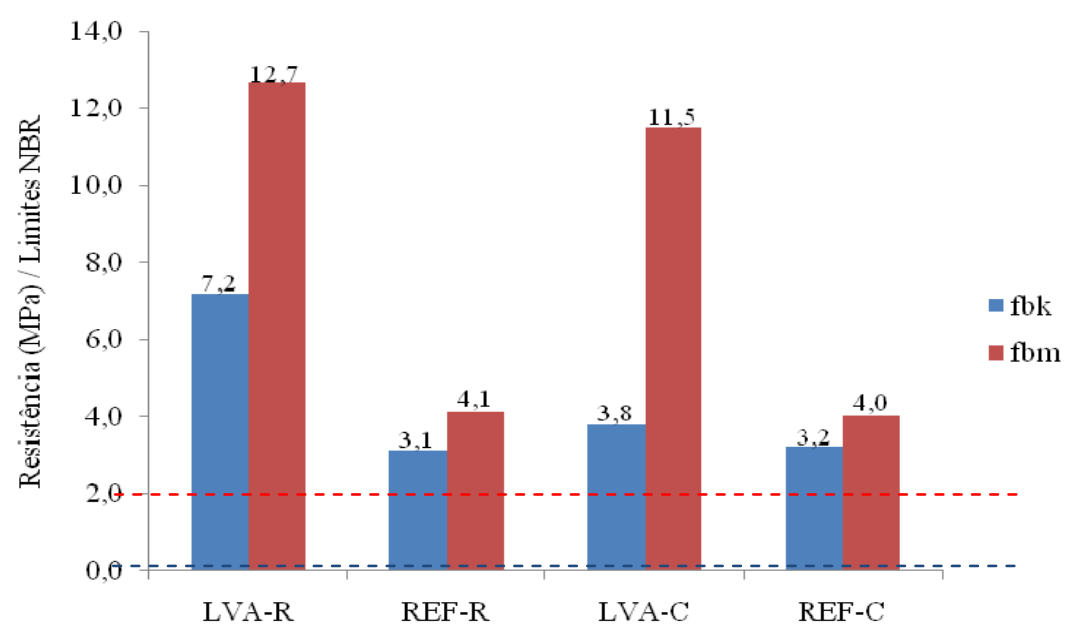

Figura 6 - Comparativo da resistência à compressão dos blocos com os limites normativos

Quanto à resistência à compressão, todos os conjuntos de blocos apresentaram níveis compatíveis para a aplicação estrutural com resistências individuais e características $\left(\mathrm{f}_{\mathrm{bk}}\right)$ superiores a $3 \mathrm{Mpa}$, definido como limite mínimo pela NBR 15270-2 (ABNT, 2005a) para o valor característico (Figura 6). As resistências médias para os blocos produzidos com a mistura LV e argila $\left(f_{b m}\right)$ também são adequadas quando comparadas com a resistência mínima de 4,5 Mpa, estabelecida pela NBR 6136 (ABNT, 1994) para blocos estruturais de concreto de (Figura 6), e superiores às resistências dos blocos de referência.

Em termos percentuais, a resistência média dos blocos com adição de lama vermelha e argila foi $210 \%$ e $188 \%$ mais alta que as resistências dos blocos de referência para as geometrias reticulada e circular respectivamente. Para os valores característicos, esse acréscimo de resistência em favor dos blocos com mistura de LV e argila em relação aos blocos de referência ficou em 132\% e $19 \%$ para as geometrias reticulada e circular respectivamente. Quanto à geometria dos blocos, observa-se que não há grandes diferenças entre os padrões reticulado e circular, exceto para a resistência característica do bloco com a mistura LV e argila, em que o valor do padrão reticulado ficou bem superior ao do padrão circular.

Os resultados de resistência para os blocos de referência apresentaram um desvio padrão muito menor, indicando maior uniformidade quanto às características do material empregado (argila). A alta dispersão dos resultados de resistência à compressão para as amostras com mistura de LV e argila provavelmente está relacionada com a elevada contração de secagem, podendo ocasionar fissuras que fragilizam a estrutura do material, e podem também estar relacionadas com variações na dosagem dos componentes durante o processo de fabricação dos blocos. Os níveis mais altos de resistências à compressão, obtidos para as amostras produzidas a partir da mistura LV e argila, estão relacionados à quantidade significativamente maior de fundentes introduzidas no sistema pela adição da LV, que favorece também o aumento do teor de mulita secundária. Os resultados obtidos neste estudo foram bem mais expressivos que os resultados obtidos por Gouveia (2006), que obteve uma resistência média de aproximadamente $4 \mathrm{MPa}$ para blocos produzidos para a mesma proporção de argila e LV. A razão para essa diferença pode estar no fato de que a temperatura utilizada por Gouveia (2006) foi mais baixa $\left(900{ }^{\circ} \mathrm{C}\right)$, o que reduziu o potencial de sinterização, não tendo o mesmo índice de formação de mulita obtido neste estudo.

\section{Conclusões}

De acordo com os resultados obtidos, conclui-se que a utilização da lama vermelha em mistura com a argila para fabricação de blocos cerâmicos estruturais é tecnicamente viável do ponto de vista de absorção de água e resistência à compressão. $\mathrm{O}$ menor índice de absorção de água (porosidade) e a maior resistência mecânica associada às amostras produzidas com a mistura de LV e argila devem-se ao acréscimo de elementos fundentes introduzidos pela adição de LV, que aumenta a eficiência das reações de estado sólido mediante a formação de mais fase amorfa, reduzindo a porosidade e aumentando significativamente a resistência à compressão dos blocos cerâmicos. A dosagem de $60 \%$ de LV e de $40 \%$ de argila mostrou-se viável para a produção dos blocos cerâmicos estruturais, porém é necessário um controle mais rigoroso desses teores na mistura para evitar variações acentuadas nas propriedades físicas e mecânicas dos blocos, pois alguns compostos, como o $\mathrm{Na}$ e as 
zeólitas presentes na $\mathrm{LV}$, produzem elevados índices de retração na mistura, principalmente durante a secagem, afetando a conformidade dimensional dos blocos e a resistência mecânica. Os problemas relacionados às variações de altura, comprimento, largura e espessura dos septos observadas nas caracterizações de conformidade dimensional podem ser controlados com ajustes nas dimensões dos moldes e das boquilhas utilizadas na fabricação dos blocos. Já os problemas relacionados à resistência mecânica podem ser minimizados por meio do controle da velocidade de secagem, minimizando o surgimento de trincas. Em ambos os casos é necessário controle na dosagem de LV para evitar diferentes níveis de contração pós-secagem.

\section{Referências bibliográficas}

ASSOCIAÇÃO BRASILEIRA DE NORMAS TÉCNICAS. NBR-7171: bloco cerâmico para alvenaria. Rio de Janeiro, 1992.

\section{ASSOCIAÇÃO BRASILEIRA DE NORMAS}

TÉCNICAS. NBR-6136: bloco vazado de concreto simples para alvenaria estrutura. Rio de Janeiro, 1994.

\section{ASSOCIAÇÃO BRASILEIRA DE NORMAS \\ TÉCNICAS. NBR-15270-2: componentes} cerâmicos: parte 2: blocos cerâmicos para alvenaria estrutural - terminologia e requisitos. Rio de Janeiro, 2005a.

\section{ASSOCIAÇÃO BRASILEIRA DE NORMAS TÉCNICAS. NBR-15270-3: componentes cerâmicos: parte 3: blocos cerâmicos para alvenaria estrutural e de vedação: método de ensaio. Rio de Janeiro, 2005b.}

ALUNORTE. Alumina do Norte do Brasil S/A. Relatório Administrativo Anual de 2008. 2008. Disponível em: <http://www.alunorte.net>. Acesso em: 21 jun. 2010.

BRUNORI, C. et al. Reuse of a Treated Red Mud Bauxite Waste: studies on environmental compatibility. Journal of Hazardous Materials, v. 117, n. 1, p. 55-63, jan. 2005.

ENVIRONMENTAL PROTECY AGENCY. Electronic Code of Federal Regulations: title 40, part 261, sect 4(b) (7) (ii) (C). Disponível em: $<$ http://ecfr.gpoaccess.gov>. Acesso em: $21 \mathrm{dez}$. 2011.
GOUVEIA, F. P. A Utilização da Lama Vermelha (LV) Como Matéria-Prima Para Produção de Blocos Cerâmicos Estruturais Destinados a Indústria da Construção Civil. Belém, 2006. Trabalho de Conclusão de Curso (Graduação) - Faculdade de Engenharia Civil, Universidade Federal do Pará, Belém, 2006.

HILDEBRANDO, E. A. Aplicação do Rejeito do Processo Bayer (Lama Vermelha) Como Matéria-Prima na Indústria de Cerâmica. 1998. 82 f. Dissertação (Mestrado em Engenharia Civil) - Escola de Engenharia, Universidade Federal do Pará, Belém, 1998.

HIND, R. A.; BHARGAVA, S. K.; GROCOTT, S. C. The Surface Chemistry of Bayer Process Solids: a review. Colloids and Surfaces A:

Physicochemical and Engineering Aspects, v. 146, p. 359-374, 1999.

LIMA, F. S. S. Utilização da Lama Vermelha e do Resíduo Caulinítico na Produção de Pigmento Pozolânico para Argamassas e Concretos de Cimento Portland. 2006. Dissertação (Mestrado em Engenharia Civil) Programa de Pós-Graduação em Engenharia Civil, Universidade Federal do Pará, Belém, 2006.

NORTON, F. H. Introdução à Tecnologia Cerâmica. São Paulo, Edgar Blucher. 1973. 324 p.

PEDROTI, L. G. et al. Resultados em Ensaios de Blocos cerâmicos Prensados e Queimados. In: CONGRESSO BRASILEIRO DE CERÂMICA, 51., Salvador, 2007. Anais... Salvador, 2007. v. 1.

REESE, K. M., CUNDIFF, W. H. In Aluminum Production the First Stage is Alumina. Industrial and Engineering Chemistry, v. 47, n. 9, p. 16721680, 1955.

SANTOS, A. M.; OROFINO, C. R.; SOUZA, J. A. Lixiviação do Sódio Como Marcador em Produtos Industrializados (Telhas Prensadas) pela Norma NBR 1005 ABNT, a Partir da Mistura ArgilaLama Vermelha. In: CONGRESSO BRASILEIRO DE CERÂMICA, 45., Florianópolis, 2001.

Anais... Florianópolis, 2001. v. 1.

SILVA FILHO, E. B.; ALVES, M. C.; DA MOTTA, M. Lama Vermelha da Indústria de Beneficiamento de Alumina: produção, características, disposição e aplicações alternativas. Revista Matéria, v. 12, n. 2, p. 322338, 2007.

SOUZA, J. A. S.; NEVES, R. F.; HILDEBRANDO, E. A. Estudo da Estabilidade de sódio e Hidróxido Residual por Lixiviação no Material Cerâmico, Produzido a Partir da Mistura Argila Lama Vermelha (Resíduo do Processo Bayer). In: CONGRESSO BRASILEIRO DE 
CERÂMICA, 44., São Paulo, SP, 2000. Anais... São Paulo, SP, 2000. v. 1.

SOUZA, J. A. S.; MACÊDO, E. N.;

QUARESMA, J. N. Reciclagem de Resíduos da Indústria de Alumina. In: Relatório Final: convênio n. 867 UFPA/FADESP/ALUNORTE S.A. Subprojeto. 2002.

SOUZA, J. A. S. Reciclagem da Lama Vermelha Como Matéria Prima para Indústria de Cerâmica Vermelha. In: Relatório Técnico: convênio UFPA/ALUNORTE S.A. Barcarena/PA, 2006.

SOUZA, J. A. S. Utilização de Resíduo do Processo Bayer Como Matéria Prima na Produção de Agregado. 2010. Tese (Doutorado em Engenharia Civil) - Programa de Doutorado em Recursos Naturais da Amazônia, Universidade Federal do Pará, Belém, 2010.

SOUZA, J. A. S. et al. Reciclagem de Lama Vermelha Oriunda da Indústria de Alumina na Fabricação de Blocos Vazados para a Construção Civil. In: CONGRESSO BRASILEIRO DE CERÂMICA, 54., Foz do Iguaçu, 2010. Anais... Foz do Iguaçu, 2010. v. 1.

VIEIRA, T. M. Produção de Agregado Utilizando Lama Vermelha: caracterização microestrutural visando sua aplicação em concreto. 2008. Dissertação (Mestrado em Engenharia Químical) - Programa de Pós-Graduação em Engenharia Química, Universidade Federal do Pará, Belém, 2008.

Revista Ambiente Construído

Associação Nacional de Tecnologia do Ambiente Construído

Av. Osvaldo Aranha, 99 - 3o andar, Centro

Porto Alegre - RS - Brasil

CEP $90035-190$

Telefone: +55 (51) 3308-4084

Fax: +55 (51) 3308-4054

www. seer. ufrgs. br/ ambienteconstruido 